\title{
Urgences
}

\section{Fièvre phare}

\section{Nicole Brossard}

Numéro 33, octobre 1991

Poésies parallèles : France - Québec

URI : https://id.erudit.org/iderudit/025668ar

DOI : https://doi.org/10.7202/025668ar

Aller au sommaire du numéro

Éditeur(s)

Urgences

ISSN

0226-9554 (imprimé)

1927-3924 (numérique)

Découvrir la revue

Citer ce document

Brossard, N. (1991). Fièvre phare. Urgences, (33).

https://doi.org/10.7202/025668ar d'utilisation que vous pouvez consulter en ligne.

https://apropos.erudit.org/fr/usagers/politique-dutilisation/ 


\section{Fièvre phare}

Nicole Brossard

ce sont touiours les mêmes mots

grands objets de paroles

lumière, nuit ou silence

les mêmes oiseaux l'après-midi

le bruit de l'automne

un autre paragraphe

en deçà des mots

quand je respire

la réponse qui fuit

nos rêves, nos rêves

et d'autres inventions charnelles

notre sourire inexplicable

bien sûr, la mer éveille

en nous, toute la nuit

chose qui prétend paisible

devenir 
la tragédie dérive notre souffrance est une chaleur qui gagne l'avenir avec des intuitions de bonheur tout est prêt pour nos lèvres pour la fureur d'autres décisions à propos l'éternité puis le mot est vague je m'installe dans l'après-midi ombre calculée $j e$ au bout des pensées 
72

il est vrai que le style est une attitude pour rompre à l'infini

la proposition de mort très digne on supplie au milieu d'une phrase

la mort n'a de sexe qu'un je

l'avenir continue, le siècle est cri toujours cette confiance

car mourir nous l'avons dit mille fois en éclats pour comprendre

le nowhere de la fièvre phare far away 
puis je respire sans réconcilier

le mensonge et nos gènes dramatiques

lhistoire et la couleur du bleu

ce sont toujours les mêmes mots

nos rêves, nos rêves

les objets sur la table de travail

les mêmes oiseaux l'après-midi

ferveur, langueur

un autre paragraphe

on se perche sur la vérité

notre corps prétend que notre corps

respire bien dans l'irréel 
74

il est vrai que le style provoque

des réponses, très digne on acquiesce je lève les yeux

le soleil se déplace lentement

au milieu des stylos et des phrases

il est tôt encore

les mêmes oiseaux

la réponse qui fuit

nowhere

fièvre, ici table de travail

il est bon de répéter

parmi les planètes

n'oubliant point le rose

la matière vivante, nos frissons soudains

nos rêves, nos rêves

notre sourire inexplicable 